\title{
Testing of High-Power Traction Batteries
}

\author{
Johannes Büdel', Johannes Teigelkötter ${ }^{1}$ Alexander Stock ${ }^{1}$, Kai Kuhlmann ${ }^{1}$, Klaus Lang ${ }^{2}$, Patrik Ott ${ }^{2}$ \\ ${ }^{1}$ Technische Hochschule Aschaffenburg, Würzburger Str. 45, D-63743 Aschaffenburg, \\ ${ }^{2}$ Hottinger Brüel \& Kjaer GmbH, Im Tiefen See 45, D-64293 Darmstadt \\ Johannes.Teigelkoetter@th-ab.de
}

\begin{abstract}
Summary:
Electric drives in road vehicles with a battery as energy storage are about to be introduced to the mass market. In order to guarantee the quality and operational safety of battery-powered vehicles, considerable efforts must be made by car manufacturers and their suppliers. Since the properties of the batteries significantly determine the performance of the vehicles, special test benches with precise measuring systems are required for the accurate determination of the battery properties. The safety devices of the traction batteries must also be tested on high-performance test benches. In this paper the necessary test benches and the corresponding measuring systems are presented. Estimations of the measurement uncertainty and possibilities to increase measurement accuracy are presented.
\end{abstract}

Keywords: Mobility, Batteries, Test Benches, High Performance Measurement System, Current Measurement

\section{High-Power Traction Batteries}

With a value share of approx. $40 \%$, the traction battery is not only an essential technical component, but also significantly determines the total manufacturing costs of an electric vehicle. The traction battery, as shown in fig. 1, consists of a combination of individual battery modules. For achieving a module voltage of approx. $32 \mathrm{~V}$ to $50 \mathrm{~V}$, several chemical cells are connected in series. Different Li-lon technologies are used in modern and powerful battery systems. The modules are connected in series and parallel, depending on the required power and energy of the vehicle. The total voltage of the traction battery is usually in the range of $300 \mathrm{~V}$ to $1000 \mathrm{~V}$. The battery management system (BMS) monitors and activates the output voltage for the drive train and other consumers [1].

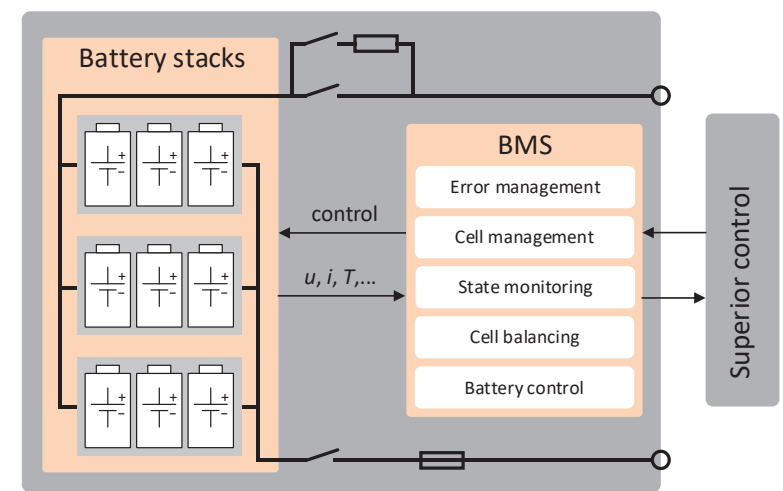

Fig. 1. Typical structure of a battery system

\section{High-Performance Test Bench}

In accordance with the individual requirements of high-power traction batteries, a corresponding test bench has to fulfil those specifications for the test procedures. The main focus of this test bench is to provide the most flexible test execution and a high power range of the future batteries. The execution of the test procedures has to be as realistic and application-oriented as possible. Considering the requirements for the process of testing a high-power traction battery, a unique high-performance test bench for these systems is presented in fig. 2 [2].

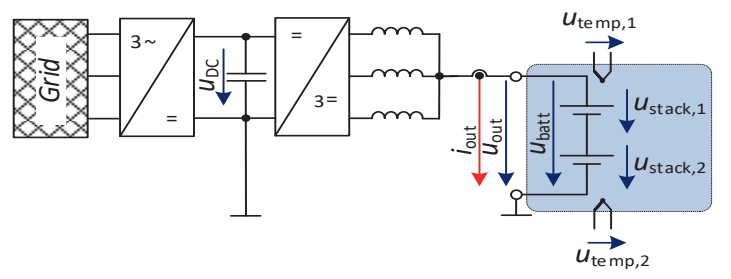

Fig 2. Basic structure of the test system

The power electronic interface of the test bench consists of two two-level converters, connected via the shared dc-link. The three half-bridges of the output dc-dc converter are controlling the battery current, while the grid side converter controls the dc-link voltage and the grid current. With this configuration, the test bench allows a bidirectional power flow, with a maximum operating power of $250 \mathrm{kVA}$, an output voltage range of 0 $750 \mathrm{~V}$ and a maximum output current up to \pm $800 \mathrm{~A}$. 


\section{Determination of the Battery DC Resistance}

Besides the battery capacity, the internal resistance is also one of the major battery parameters. The lower the resistance, the less the restriction the battery encounters in delivering the needed power spikes. Figure 3 presents a technique to measure the $D C$ resistance of a battery. This method is based on the voltage change during a current step. Ideally, the current jumps from a small value (e.g. 0.1 C-Rate) to a high value (e.g. 2 C-Rate). After a defined duration, the voltage drop is measured [3]. According to this procedure the resistance is calculated with eq. 1 . $R_{D C}=\frac{\Delta U}{\Delta I}$
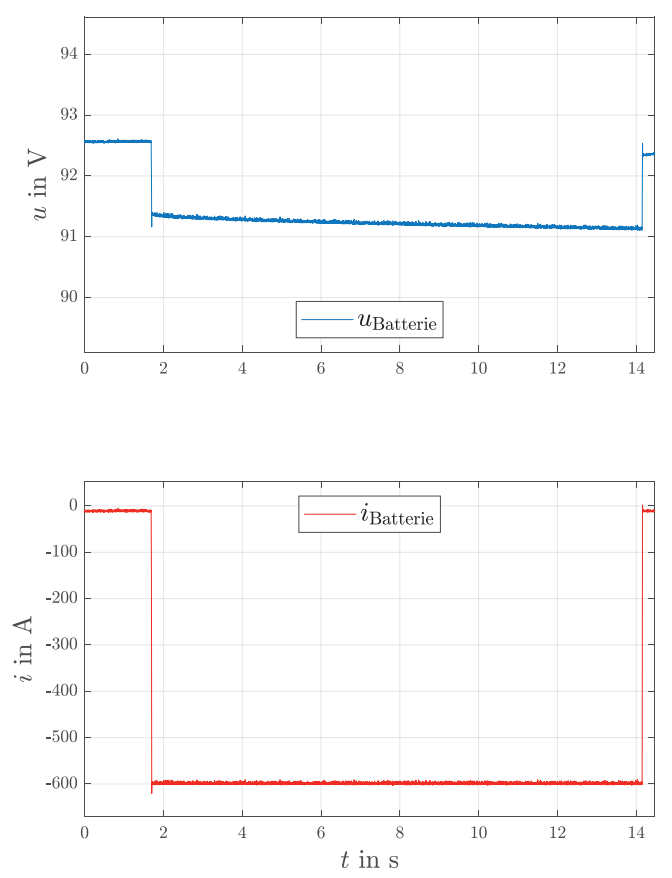

Fig. 3. Measurement of DC-Resistance

\section{Short circuit test on a traction battery}

The Battery Management System (BMS) is responsible for monitoring and protecting a battery system. During normal operation, this BMS determines the charge level of a traction battery and takes over communication with the vehicle computer. The safety electronics with the cut-off device are also installed here, which are intended to disconnect the battery from the boardnet in the event of a fault. To test this safety electronics, a low-resistance short circuit is provoked. Thereupon, a short-circuit current flows, which must be switched off by the safety electronics within a short time with the help of special switch-off devices.

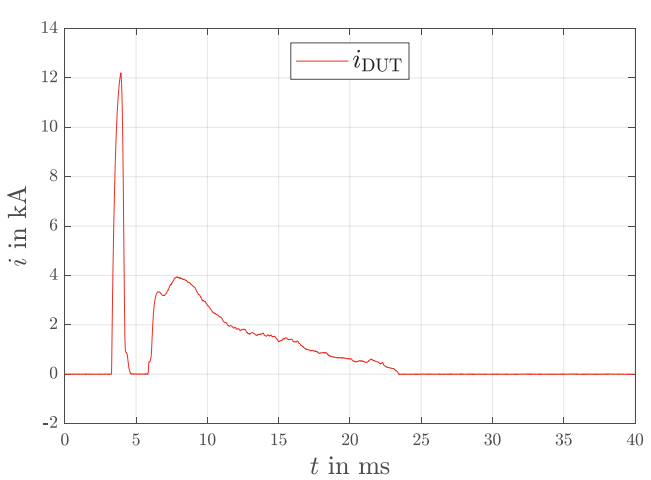

Fig. 4: Waveform of the short-circuit current measured with a shunt

The waveform of a typical short-current is shown in fig. 4. This current reaches a peak value of about $12 \mathrm{kA}$ at $t=4 \mathrm{~ms}$. After the short-circuit current has been interrupted, obviously, the current rises again up to $4 \mathrm{kA}$. This behavior is not acceptable for reliable operation. To find out the reason for this malfunction it has to be checked if the current was really interrupted at $t=5 \mathrm{~ms}$ or if a small current was still flowing.

This short-circuit current measurement sets high demands on the measurement technology. In order to absorb the strong mechanical forces, which are acting due to the large currents, the current sensors must be designed very stable. To capture the fast current changes correctly, the bandwidth of the sensors must be sufficiently high. To ensure that the relative measurement uncertainty is independent of the actual current level, a nonlinear current sensor is proposed here. This NLCS (Nonlinear Current Sensor) was developed especially for the measurement of short circuit currents [4].

\section{References}

[1] International Electrotechnical Commission (IEC): Electrical Energy Storage, White Paper, 12/2011.

[2] Büdel, J., Teigelkötter, J., Stock, A., Kowalski, T., \& Lang, K. (2017, September). Qualification and verification of high-power battery systems for traction application. In 2017 19th European Conference on Power Electronics and Applications (EPE'17 ECCE Europe) (pp. P-1). IEEE.

[3] Jossen; Weydanz: Moderne Akkumulatoren richtig einsetzen. Untermeitingen: Inge-Reichardt-Verlag, 2006. ISBN: 3-939359-11

[4] Kurzschlussprüfung von Hochleistungs-Traktionsbatterien mit nichtlinearen Stromsensoren, HBM White Paper, www.HBM.com 